\title{
Orbital Radii and Rotation of Celestial Bodies
}

\author{
Kamil Madáć ${ }^{1 *}$, Andrej Madáč ${ }^{2}$ \\ Technická Univerzita v Košiciach, Strojnicka fakulta, Letná 9, 04200 Košice Slovakia \\ ${ }^{2}$ Senior citizen, Hroncová 15, 04001 Košice, Slovakia
}

\section{BIOGRAPHICAL NOTES}

Kamil Madáč, Doc. Ing. CSc. He is associate professor of production techniques, former head department of Department of production techniques and equipment. His study field is CA technologies and programming in Machine tools Design. He is author of 2 monographs, 2 university textbooks, 15 university books and more than 150 publications in journals and conference proceedings at Slovakia and abroad.

Andrej Madáč, Ing. He graduated at TU Košice, 1985. He was a manager in US Steel Košice until 1998. Now he interesting in physics and astronomy. His main publication was paper: The measurement of speed of gravitational wave. In: Kybernetes. Vol. 32, no. 7/8 (2003), p. 1138-1141. - ISSN 0368-492X

\section{KEY WORDS}

Acceleration due to gravity, orbital radius, rotation.

\section{ABSTRACT}

Orbital radii of the planets and moons are considered to be random. The predominant view says that planets and moons can orbit at any radius, similarly to satellites which can be placed at various orbits if only their orbital speed is correct one. Defining of orbital radii of the Sun's planets on their physical nature basis is unknown. The article aims to contribute to the knowledge and reasons of celestial bodies' orbital radii and about the reason of their rotation.

\section{Introduction}

The cause of orbital radii of Solar system planets is not known. Basically, there is no theory to explain this on the basis of the nature of gravity. That is why we cannot quote the links to authors who published on this topic in the past. Obviously, except the mathematical rule (Titius, Bode, 1772) [1, 2] .

The experiment was carried in 2002 [3] aimed at gravity monitoring of the Moon movement across the sky. The analysis of the obtained data has leaded us to knowledge of celestial bodies' radii subordination to the product of their radius and density.

\section{Orbital Radii of Moons}

At first we will deal with two physical physical quantities which have a verifiable impact on the orbital radii of moons:

1. Acceleration due to gravity $g$ on the moon surface.

2. Acceleration due to gravity $g_{\text {orb }}$ of the planet on the orbit of the moon.

The ratio of these quantities is important in order to define the orbital radius of the moon. Let us have a look on the ratio $\mathrm{g} / \mathrm{g}_{\text {orb }}$ impact on the orbital radii of Jupiter, Saturn and Uranus moons. We only considered the moons of spherical shape which look homogenous. We did not consider the moon of Saturn - lapetus and the one of 
Uranus - Miranda which we consider to be nonstandard. Neptune has the only moon of spherical shape - Triton - which features a regressive orbital motion way. Table. 1 presents the dependency ratio of $\mathrm{g} / \mathrm{g}_{\text {orb }}$ for the moons of the listed planets on their orbital radius.
Jupiter - (lo, Europa, Ganymedes, Callisto). m Saturn - (Mimas, Enceladus, Thetys, Dione, Rhea, Titan). - Uranus - (Ariel, Umbriel, Titania, Oberon).

The information was obtained from [4]. The radius R value considered was: Orbit Size (semi-major axis).

Table 1: Parameters of the moons of Jovian (gas) planets.

\begin{tabular}{|c|c|c|c|c|c|c|}
\hline & $\mathbf{r}[\mathbf{m}]$ & m [kg] & $\mathbf{R}[\mathrm{m}]$ & & & $\boldsymbol{g} / \boldsymbol{g}$ \\
\hline JUPITER & 69911000 & $1,90 \mathrm{E}+27$ & & & {$\left[\mathrm{~m} . \mathrm{s}^{-2}\right]$} & g/gorb \\
\hline Io & 1821600 & $8,93 \mathrm{E}+22$ & $4,22 \mathrm{E}+08$ & $1,80 \mathrm{E}+00$ & $7,13 \mathrm{E}-01$ & 2,52 \\
\hline Europa & 1560800 & $4,80 \mathrm{E}+22$ & $6,71 \mathrm{E}+08$ & $1,31 \mathrm{E}+00$ & $2,82 \mathrm{E}-01$ & 4,67 \\
\hline Ganymedes & 2631200 & $1,48 \mathrm{E}+23$ & $1,08 \mathrm{E}+09$ & $1,43 \mathrm{E}+00$ & $1,10 \mathrm{E}-01$ & 13,04 \\
\hline Calisto & 2410300 & $1,08 \mathrm{E}+23$ & $1,88 \mathrm{E}+09$ & $1,24 \mathrm{E}+00$ & $3,58 \mathrm{E}-02$ & 34,55 \\
\hline
\end{tabular}

\begin{tabular}{|c|c|c|c|c|c|c|}
\hline & $\mathbf{r}[\mathbf{m}]$ & m [kg] & $\mathbf{R}[\mathrm{m}]$ & g & $g_{o r b}$ & $\alpha / \alpha$ \\
\hline SATURN & 58232000 & $5,68 \mathrm{E}+26$ & $\mathrm{~K}$ [III] & {$\left[\mathrm{m} \cdot \mathrm{s}^{-2}\right]$} & {$\left[\mathrm{m} \cdot \mathrm{s}^{-2}\right]$} & g/gorb \\
\hline Mimas & 198200 & $3,75 \mathrm{E}+19$ & $1,86 \mathrm{E}+08$ & $6,37 \mathrm{E}-02$ & $1,10 \mathrm{E}+00$ & 0,06 \\
\hline Enceladus & 252100 & $1,08 \mathrm{E}+20$ & $2,38 \mathrm{E}+08$ & $1,13 \mathrm{E}-01$ & $6,69 \mathrm{E}-01$ & 0,17 \\
\hline Tethys & 533000 & $6,18 \mathrm{E}+20$ & $2,95 \mathrm{E}+08$ & $1,45 \mathrm{E}-01$ & $4,37 \mathrm{E}-01$ & 0,33 \\
\hline Dione & 561700 & $1,10 \mathrm{E}+21$ & $3,77 \mathrm{E}+08$ & $2,32 \mathrm{E}-01$ & $2,66 \mathrm{E}-01$ & 0,87 \\
\hline Rhea & 764300 & $2,31 \mathrm{E}+21$ & $5,27 \mathrm{E}+08$ & $2,64 \mathrm{E}-01$ & $1,36 \mathrm{E}-01$ & 1,93 \\
\hline Titan & 2574700 & $1,35 \mathrm{E}+23$ & $1,22 \mathrm{E}+09$ & $1,35 \mathrm{E}+00$ & $2,54 \mathrm{E}-02$ & 53,35 \\
\hline
\end{tabular}

\begin{tabular}{|c|c|c|c|c|c|c|}
\hline & $\mathbf{r}[\mathbf{m}]$ & m [kg] & \multirow{2}{*}{$\mathbf{R}[\mathrm{m}]$} & \multirow{2}{*}[\mathrm{m}\cdot\mathrm{s}^{-2}]{} & \multirow{2}{*}{$\begin{array}{c}\boldsymbol{g}_{\text {orb }} \\
{\left[\mathrm{m} \cdot \mathrm{s}^{-2}\right]}\end{array}$} & \multirow{2}{*}{$g / g_{\text {orb }}$} \\
\hline URANUS & 25362000 & $8,68 \mathrm{E}+25$ & & & & \\
\hline Ariel & 578900 & $1,295 \mathrm{E}+21$ & $1,91 \mathrm{E}+08$ & $2,58 \mathrm{E}-01$ & $1,59 \mathrm{E}-01$ & 1,62 \\
\hline Umbriel & 584700 & $1,221 \mathrm{E}+21$ & $2,66 \mathrm{E}+08$ & $2,38 \mathrm{E}-01$ & $8,19 \mathrm{E}-02$ & 2,91 \\
\hline Titania & 788900 & $3,420 \mathrm{E}+21$ & $4,36 \mathrm{E}+08$ & $3,67 \mathrm{E}-01$ & $3,04 \mathrm{E}-02$ & 12,05 \\
\hline Oberon & 761400 & $2,883 \mathrm{E}+21$ & $5,84 \mathrm{E}+08$ & $3,32 \mathrm{E}-01$ & $1,70 \mathrm{E}-02$ & 19,50 \\
\hline
\end{tabular}

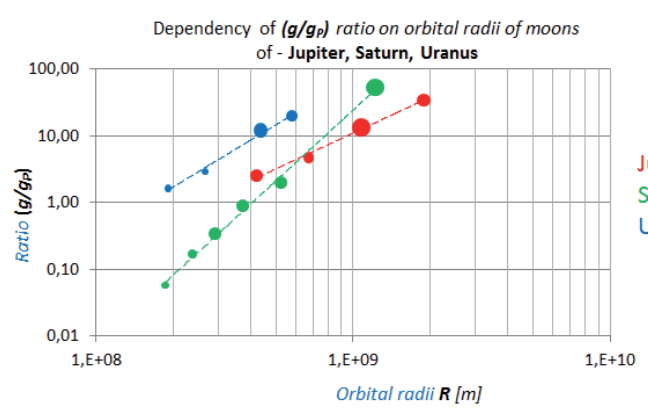

Graph 1: Ratio ( $\mathrm{g} /$ gorb) for the moons of Jupiter, Saturn and Uranus.

Coefficient $F^{2}$ (Least Square Fiting) - Jupiter $F^{2}=$ 0,9932, Saturn $F^{2}=0,9961$ and Uranus $F^{2}=0,9897$, prove that the ratio $\left(\mathbf{g} / \mathbf{g}_{\text {orb }}\right)$ of the orbiting moons correlates with their orbital radii.

Let us have a detailed look at the ratio $g / g_{\text {orr. }}$. Acceleration due to gravity $\boldsymbol{g}$ on the surface of the moon with the radius $\boldsymbol{r}_{\boldsymbol{m}}$ and the acceleration due to gravity $\boldsymbol{g}_{\text {orb }}$ of the planet on orbital radius $\boldsymbol{R}_{\boldsymbol{m}}$ of the moon can be defined according to a well- known Newton's law of gravity. Index , $\boldsymbol{M}^{\prime \prime}$ applies to the moon, index „P $\boldsymbol{P}^{\text {“ }}$ applies to the planet. Then:

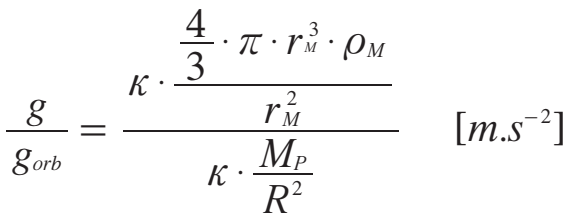

After adjustment we get the ratio:

$\frac{g}{g_{\text {orb }}}=\frac{4}{3} \cdot \pi \cdot \frac{R^{2}}{M_{P}} \cdot r_{M} \cdot \rho_{M}$

The value of ratio $\mathbf{g} / \mathbf{g}_{\text {orb }}$ according to (2) depends on:

\section{- In direct proportional:}

- The square orbital radius of the moon.

- The product of the moon radius and the moon density.

Inversely proportional: Mass of the planet.

On the basis of the above mentioned facts the following can be concluded: 
Orbital radii of the planet's moons correspond to the $\mathrm{g} / \mathrm{g}_{\text {orb }}$. actual ratio.

Knowledge: If we could move any moon to a different orbit, it would return to its original orbit after a finite number of orbits.

\section{Orbital Radii of the Solar System Planets}

Table 2 presents the parameters of the planets required for calculation of the $\mathbf{g} / \mathbf{g}_{\text {orb }}$ ratio. The data was obtained from: http://solarsystem.nasa.gov

Table 2: Parameters of the Solar System planets

\begin{tabular}{|c|c|c|c|c|c|c|}
\hline & $\mathrm{r}[\mathrm{m}]$ & m [ & & & & \\
\hline SUN & 695508000 & $1,99 \mathrm{E}-$ & & & & \\
\hline Mercury & 2439700 & $3,301 \mathrm{E}+23$ & & $3,70 \mathrm{E}+00$ & $3,96 \mathrm{E}-02$ & 93 \\
\hline Venus & & & & & & 782 \\
\hline Earth & & & & & & 1655 \\
\hline Mars & & 23 & & & & 1459 \\
\hline Jupiter & 6991 & & & $2,59 \mathrm{E}$ & & 118282 \\
\hline Saturn & & & & & $6,52 \mathrm{~F}$ & 171497 \\
\hline Uranus & 25362000 & $8,681 \mathrm{E}+25$ & $2,87 \mathrm{E}+12$ & $9,01 \mathrm{E}+00$ & $1,61 \mathrm{E}-05$ & 558738 \\
\hline Jeptune & 24622000 & $1,024 \mathrm{E}+26$ & $4,50 \mathrm{E}+12$ & $1,13 \mathrm{E}+01$ & $6,56 \mathrm{E}-06$ & 1718520 \\
\hline
\end{tabular}

Dependency ratio $\mathbf{g} / \mathbf{g}_{\text {orb }}$ to the radius of the planets orbit is shown in Graph 3. Least Square Fiting coefficient $F^{2}=0,9776$ is not so close to the value 1. But the planets (some with moons) are more complex celestial bodies than moons...

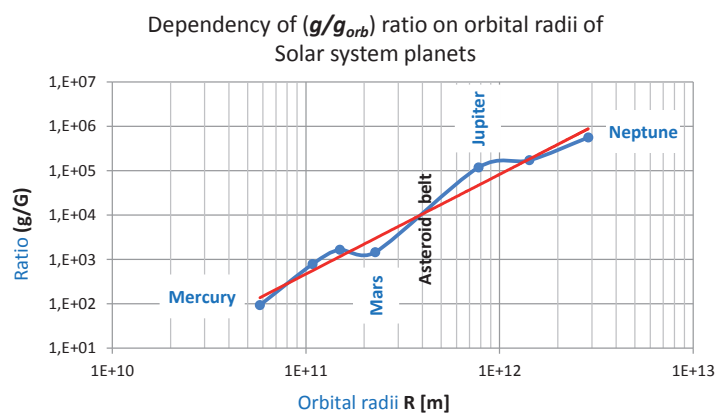

Graph 2: Ratio g/gorb of the Sun planets.

\section{Rotation of Celestial Bodies}

The results of the experiment [3] and analysis of measurement data also led us to the knowledge the gravitational field of the Sun rotates, Fig. 1 b.

a)

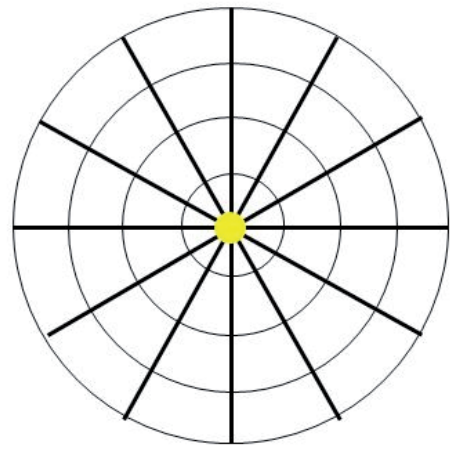

b)

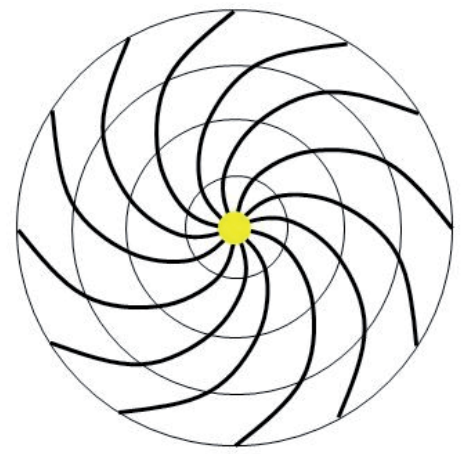

Fig. 1: The field lines of gravitational field of the Sun. a) Without field rotation - Newton, b) With field rotation

This knowledge lead to suggest that in addition to gravity by Newton Figure 1a, there is also the orbital component of gravity that is causing the orbital motions of the planets. This knowledge is important for understanding the impact of the ratio $\mathbf{g} / \mathbf{g}_{\text {or }}$ to the rotation of celestial bodies.

As discussed below, the ratio $\mathbf{g} / \mathbf{g}_{\text {orb }}$ is an important parameter not only in terms of defining the orbital radii of the heavenly bodies, but also of their rotation about its axis. Based on the analysis of the rotation of the planets in the solar system we have come to the knowledge:

\section{The planet rotates and can have moons, if the value of the ratio $\mathrm{g} / \mathrm{g}_{\text {orb }}>1000$.}

With such a high ratio $\mathbf{g} / \mathbf{g}_{\text {or }}$ is the gravitational field of the planet Fig. 2 right, formed into a gravitational field of the Sun (inside of the red circle). Rotating 
gravitational field not only causes the rotation of the planet itself, but also captures the potential moon. Gravitational field of the Sun Fig. 2 left does not act directly on the mass of the planet, but it drags the planet's gravitational field. Resultant force of grav- ity of the Sun $\boldsymbol{g}_{\mathbf{v}}$ orbit of the planet is composed of Newtonian force components $\boldsymbol{g}_{\text {orb }}$ and orbital components of $\boldsymbol{g}_{\boldsymbol{o}}$. Analogously center of the galaxy gravitational field carries the gravitational fields of stars.

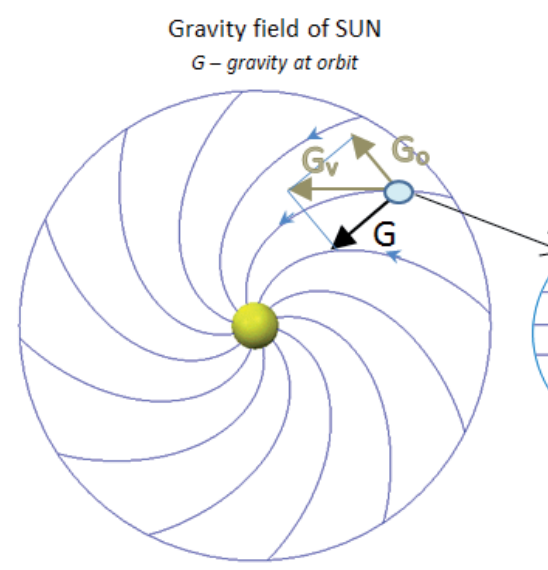

Fig. 2: Lines of force of gravitational field when $\mathrm{g} / \mathrm{g}_{\text {orb }}>1000$.

Moons of Jupiter, Saturn and Uranus, have a ratio $\mathbf{g} / \mathbf{g}_{\text {orb }}<54$. Such celestial bodies do not rotate. Moons will make one revolution around its axis during one orbit around the planet. The value of gravity in orbit of the moon $\boldsymbol{g}_{\text {orb }}$ is comparable to gravity $\boldsymbol{g}$ on its surface. Gravitational field of the moon, in this case fails to form the shape of the gravitational field of the Sun. Therefore moons do not rotate about its axis.

For celestial bodies of the Solar System applies: If the ratio $\mathbf{g} / \mathbf{g}_{\text {orb }}<1000$, celestial body does not rotate or rotates slowly (Mercury, Venus). Such celestial bodies cannot have moons.

\section{Conclusion}

The possibility of determining the value of the orbital radius of the moon on the basis of the ratio $\boldsymbol{g} /$ $\boldsymbol{g}_{\text {orb }}$ proves that the orbital radii of moons are subject to regularities that are yet unknown. Is particularly surprising dependence of the orbital radius of the moon for its density and radius! We can conclude that the orbital motion of celestial bodies impacted by the forces of gravity and inertia is a third yet unknown force.

\section{References}

[1] DUNCAN J.C.: Astronomy. Harper \& Row Publishers. New York 5. vydanie, 1955.

[2] MURRAY, Carl D., DERMOTT Stanley F. : Solar System dynamics; Cambridge University Press, 2001
Gravity field of planet $g$-gravity at surface

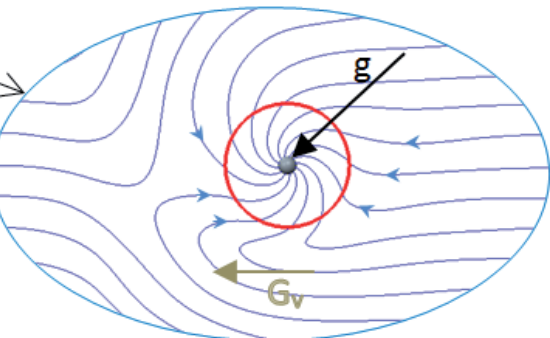

[3] MADÁČ A., MADÁČ K.: Rotácia gravitačného pola Slnka. itstrojar, http://www.it-strojar.sk/ostatne.html - SjF TU Košice. 2013

[4] http://solarsystem.nasa.gov 